\title{
Multiple masking in a backward masking paradigm
}

\author{
LEONARD PRESBY \\ William Patterson College, Wayne, New Jersey 07470 \\ SIMCHA POLLACK \\ Kean College, Union, New Jersey 07083 \\ and \\ MARK S. MAYZNER \\ Loyola University of Chicago, Chicago, Illinois 60626
}

\begin{abstract}
A study was made of the effects of multiple visual masking upon variations in mask position, word frequency, and display on time. Ten subjects were shown five-letter words, four or five letters of which were immediately masked. These words, half of which were classified as frequent and the other half as infrequent, were displayed at different display on times. Results showed that (1) exposing a little information produces the same or better results than not exposing any, (2) variations in the position of the mask cause no increase in visual performance, and (3) in total masking one position shows no better results than any other. Findings indicated both word frequency and display on time are highly significant factors, whereas the masking position is not. Results warrant a parallel processing interpretation, rather than a serial one.
\end{abstract}

Researchers have begun to treat the visual system as an information processing system. The question of whether information is transferred through stages in a parallel or serial order is still to be resolved. For example, Sperling (1963) displayed an array of letters for a few milliseconds and then substituted a pattern of dots (visual noise field) to erase the display. He found the number of items retrieved was a linear function of exposure time to masking. Thus, the subject could report one letter if the masking pattern came after $10 \mathrm{msec}$ of display, two letters if it came after $20 \mathrm{msec}$, and so on. He felt all letters were scanned at comparable rates, about one letter per $10 \mathrm{msec}$. These results suggested a process of sequential read-out from a visual image. Averbach (1963) proposed a similar view to account for the linear rise of the span of apprehension with exposure duration under conditions of masking by noise. Sperling proposed a model for visual memory tasks which provided for visual information processing first creating a short-term storage lasting a fraction of a second. He felt the content of the store was scanned, with items being processed in a serial manner, item by item, until the store either had faded away or had been erased by the new information, or until all of the information was extracted. Storage seemed to be loaded by parallel units of information and processed serially.

Weisstein (1966) believed the decision between parallel and serial processing had been made on the basis

This research was supported in part by NSF Grant GB-22785 to the last author. of whether or not there had been a total increase in response time with an increase in the size of an array. . That is, if the time between presentation and report increased for larger arrays, then serial processing had been assumed. On the other hand, if the time between presentation and report remained the same as array size increased, then parallel processing had been assumed. Weisstein felt both designs were not suggestive of one formulation over the other because an increase in processing time may mean either more operations were being performed simultaneously for each part of an array (parallel), or alternately, the set of operations was repeating itself in turn for additional parts of the array (serial).

Sekuler, Tynan, and Levinson (1973) presented brief visual stimuli in rapid sequence, one to the left and one to the right of a central fixation point. Subjects, however, reported the left stimulus as first, regardless of the actual order of presentation. (This illusion persisted under conditions of forced-choice testing and did not vary with presentation to the same or opposite retinal hemifields.) Sekuler suggested this illusion might be the product of an internal mechanism that scans visual inputs in a left-to-right order. In the present study, employing a computer-based cathode-ray-tube (CRT) display system (Mayzner, 1968; Mayzner, Tresselt, \& Helfer, 1967), the issue of sequential vs. parallel processing is approached by means of a multiple masking paradigm. For example, by varying the masking positions on the word, if we find changing the position of the mask has no effect on the subject's ability to report 
accurately, one might be inclined to feel parallel processing is taking place. Scanning, then, possibly would play little, if any, role in word recognition. Similarly, with total masking, if parallel processing is taking place, no position should have a significantly higher percentage of report than any other. But, if serial processing is taking place, then possibly the first position should fare better than any of the others.

\section{METHOD}

\section{Subjects}

Ten graduate students selected at random at the Polytechnic Institute of New York served as subjects.

\section{Apparatus}

The hardware system utilized a computer-based CRT display system. The main component was a PDP-8/E digital computer. Coupled to and driven by the computer was a CRT display console (Type VR-14). The display surface of the CRT console was coated with an ultra-short persistence phosphor (P-24) having a very short decay time (on the order of a few microseconds). Individual points could be plotted on the face of the display tube, consisting of a matrix of 1,024 by 1,024 separately programmable point locations. The individual letter size was approximately $1 \times 3 / 4$ in. Each subject, seated $2 \mathrm{ft}$ before the VR-14, was provided with prepared answer sheets for recording what was seen on each trial.

\section{Materials}

The stimulus materials consisted of the presentation of a five-letter word for a variable display on time $(5,10,20$, or $35 \mathrm{msec}$ ) which was immediately followed with a mask in either four of the five positions or in all five positions. The mask remained on for $500 \mathrm{msec}$ before termination. All letters were generated by intensifying the appropriate points of a 5 by 7 matrix of points. The mask consisted of displaying all points in the 5 by 7 matrix.

\section{Procedure}

A 2 by 4 by 6 factorial design with repeated measurements on the last two factors (Winer, 1971, pp. 539-559) was employed. Factor A (two levels) involved either the group of frequent or infrequent words. Forty eight five-letter words were chosen as frequent (frequency of 100 occurrences per million words of text) and 48 words were chosen as infrequent (frequency of 1 occurrence per million words of text) (Owsowitz, 1964). Factor B (four levels) involved the four different display on times of $5,10,20$, and $35 \mathrm{msec}$ for the individual words which were followed by the 500-msec mask. Factor C (six levels) involved masking the word in all five letter positions or four of the five letter positions. The four levels of Factor B combined with the six levels of Factor $\mathrm{C}$ to give 24 possible combinations of display on times and masks for each word. (Five of the combinations were picked for each word with the constraint that the same combination not appear more than once for the word.) Ten replicates of each combination were presented, yielding 240 different displays for each subject. The 240 trials were randomly ordered for each subject tested. Each subject took about $1 \mathrm{~h}$ for the experiment, including a 5-min break midway in the session.

\section{RESULTS AND DISCUSSION}

Table 1 summarizes the average percent correct for each position summed across the four display on times both for frequent and infrequent words. It can be seen that exposing a little information (one letter) produced
Table 1

Average Percent Correct for Each Letter Position Summed Across the Four Display On Times for Frequent and Infrequent Words

\begin{tabular}{lllllll}
\hline & & \multicolumn{5}{c}{ Letter Position } \\
\cline { 3 - 7 } & $0 *$ & 1 & 2 & 3 & 4 & 5 \\
\hline Frequent Words & 52.5 & 54 & 55 & 53 & 63.5 & 53 \\
Infrequent Words & 31 & 36.5 & 32 & 32 & 33 & 28 \\
\hline
\end{tabular}

\section{*Total mask}

the same or better results than not exposing any (total masking $=$ Position 0 ). Comparing the average percent correct with total masking over the four display on times with the average percent correct with one letter exposed over all possible conditions shows $52.5 \%$ and $56 \%$ correct responses, respectively, were obtained for the frequent words, and $31 \%$ and $33 \%$ correct responses, respectively, were obtained for the infrequent words. For frequent words, the percent correct report for total masking was always lower than for exposing any one position, while, for infrequent words, it was lower four of the five times. Of equal importance to the above was the finding that exposure of just one letter caused no interference to the subject's processing ability. Based on other theoretical considerations, such as lateral inhibition, one might have supposed that exposure of only one letter could have caused some interference in the subject's ability to process correctly the five-letter word.

Figures 1 and 2 and Table 1 illustrate that variations

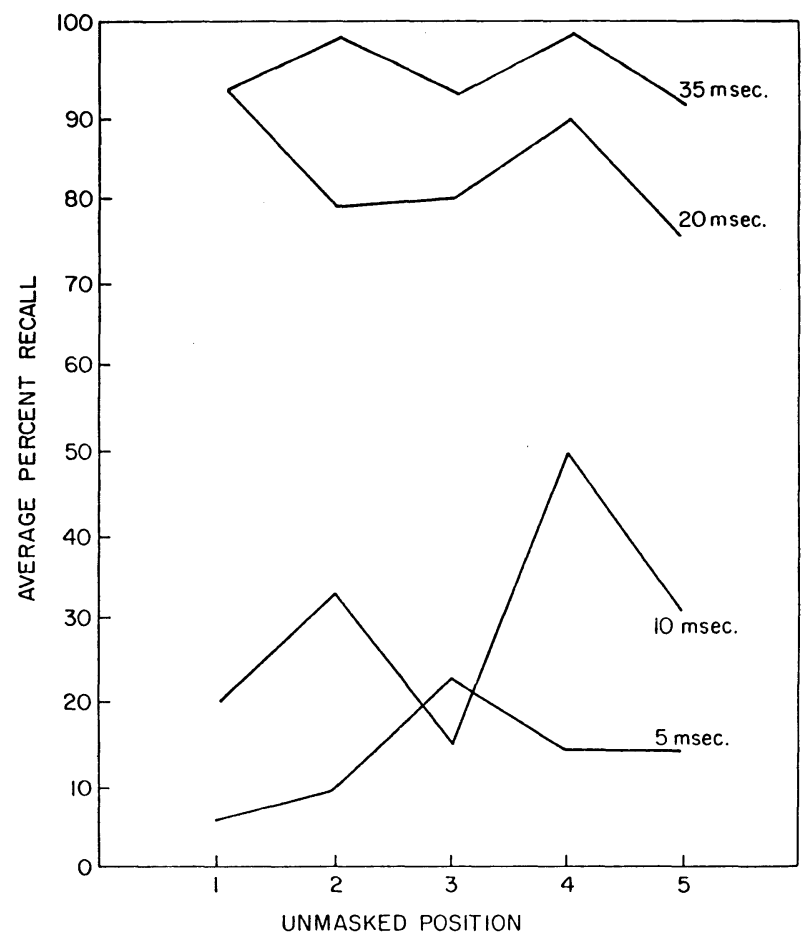

Figure 1. Average percent report as a function of unmasked position for the frequent words. 


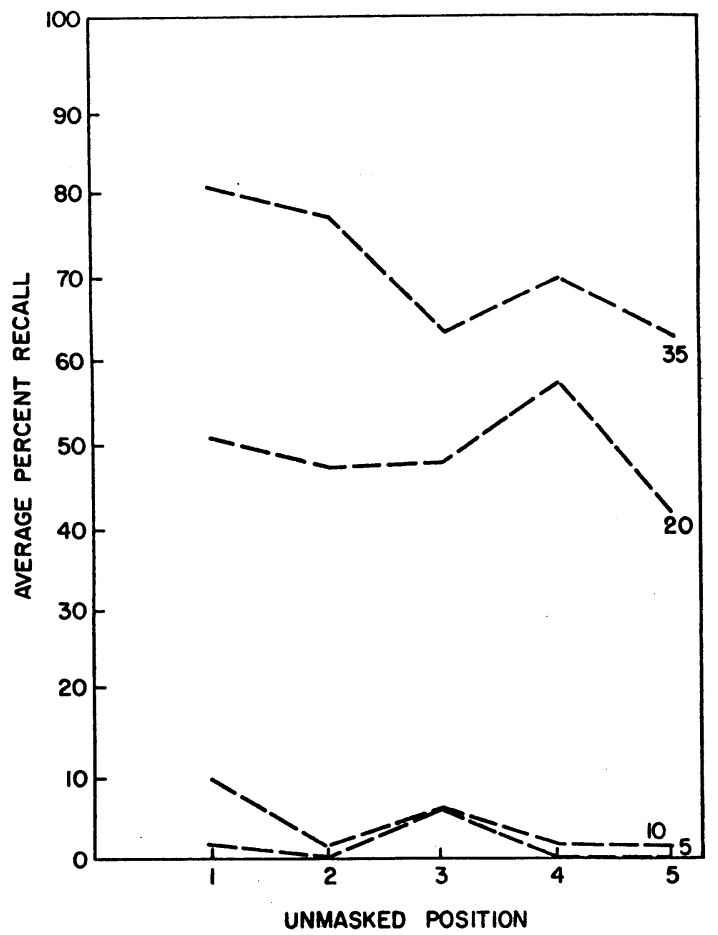

Figure 2. Average percent report as a function of unmasked position for the infrequent words.

in the position of the mask caused no increase in visual performance. There was no noticeable trend for either frequent or infrequent words. Moreover, Table 1 shows all positions are within a few percent of each other. Since percent correct report scores were employed as the dependent response measure, an inverse sine transformation was applied to the raw scores prior to the ANOVA, as recommended by Edwards (1968, pp. 106107). The ANOVA did not find Factor B (positions) to be significant $[\mathrm{F}(4,32)=1.6, \mathrm{p}>.10]$. Position, then, did not seem to play a crucial factor in the subject's processing ability. This finding would indicate sequential scanning perhaps plays little, if any, role in word recognition. Similarly, in total masking, reports of one position again did not show better results than any other. This is borne out in Figure 3, where no trend across letter positions can be discerned. From the above, there seemed to be no evidence that an internal mechanism scans the visual inputs in any left-to-right order. The above findings, on the other hand, lend themselves to a parallel processing interpretation.

Presenting a subject with frequent words results in significantly better scores than presenting him with infrequent words. For frequent words, subjects recalled $55 \%$ correct but only $32 \%$ for infrequent. The ANOVA showed that for condition $A$ (word frequency) $F(1,8)=$ $39.6, \mathrm{p}<.001$.

It is also clearly seen that an increase in display on time caused an increase in visual performance for any given condition. Factor $\mathrm{C}$ (time) was highly significant $(p<.001)$. The average percent correct report for each

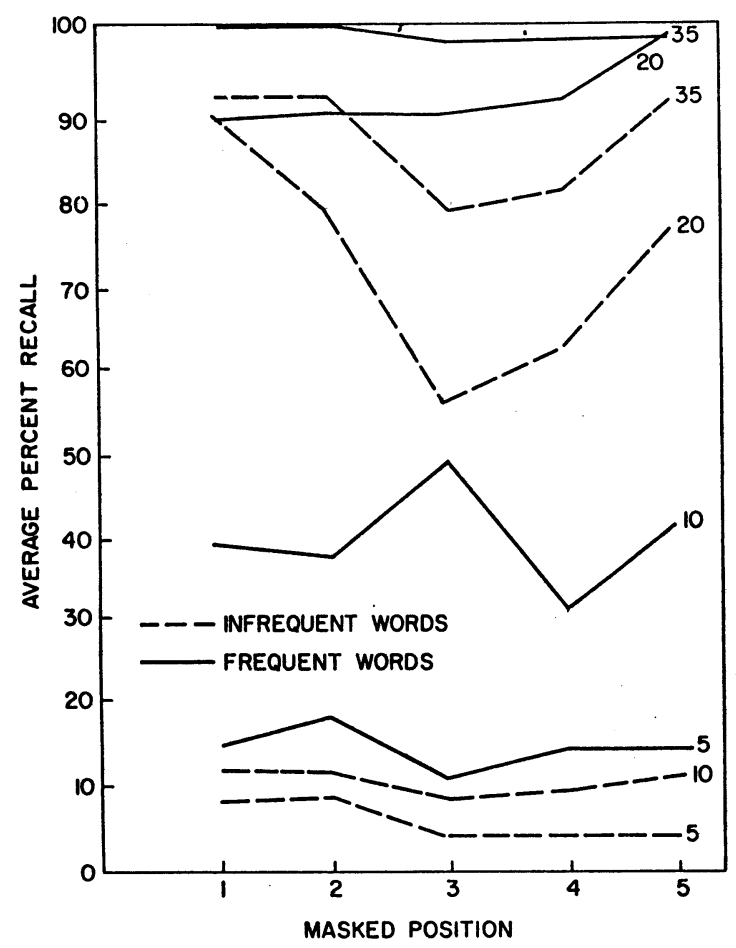

Figure 3. Average percent report as a function of masked position for the frequent and infrequent words.

time is summarized in Figure 4. For infrequent words, the low was $2 \%$ and increased to over $72 \%$. The largest jump was in the zone between 10 and $20 \mathrm{msec}$. Even though the increase was not that large between 5 and

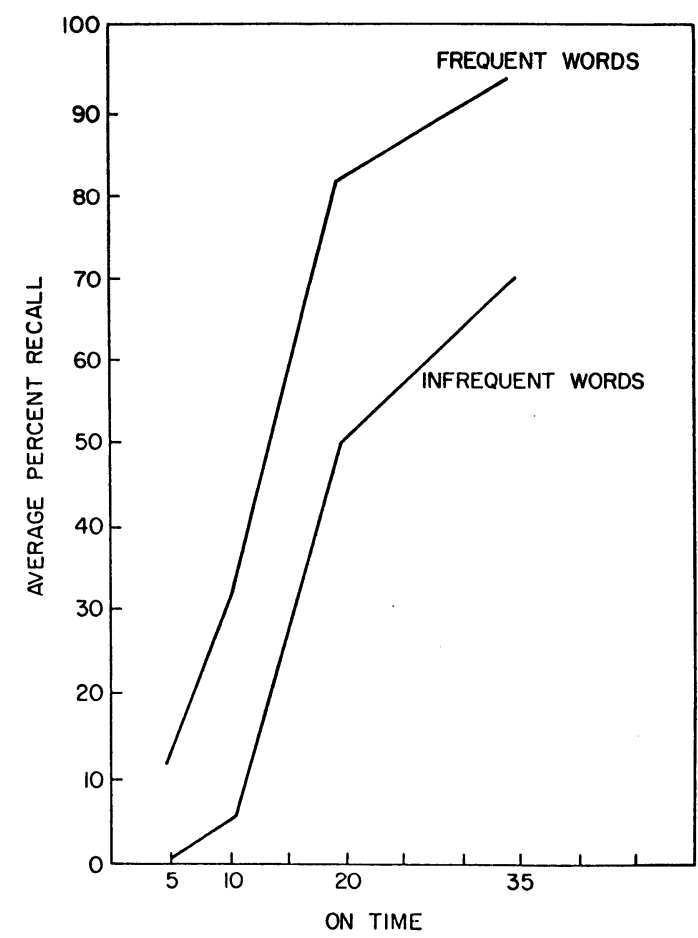

Figure 4. Average percent report as a function of display on time for the frequent and infrequent words. 
$10 \mathrm{msec}$, the fact that this increase existed in 21 of the 24 times between 5 and $10 \mathrm{msec}$ suggests a very sensitive visual information processing system in the temporal domain, as reported earlier (Mayzner, Tresselt, Checkes, $\&$ Hoenig, 1970) with an overprinting paradigm.

\section{REFERENCES}

AVERBACH, E. The span of apprehension as a function of exposure duration. Journal of Verbal Learning and Verbal Behavior, $1963,2,60-74$.

EDWARDS, A. L. Experimental design in psychological research. New York: Holt, Rinehart, \& Winston, 1968.

MAYZNER, M. S. The research potential of a computer-based cathode-ray-tube display system. Behavior Research Methods \& Instrumentation, 1968, 1, 41-43.

Mayzner, M. S., Tresselt, M. E., Checkes, J., \& Hoenig, H. A. Visual information processing of sequentially presented inputs: III. Further effects of list length and interstimulus interval values on sub-span storage and retrieval mechanisms. Psychonomic Monograph Supplements, 1970, 7, 294-296.
Mayzner, M. S. Tresselt, M. E., \& Helfer, M. S. A research strategy for studying certain effects of very fast sequential input rates on the visual system. Psychonomic Monograph Supplements, 1967, 2(5, Whole No. 21), 73-81.

Ow sowitz, S. E. The effects of word familiarity and letter structure familiarity on the perception of words. Rand Corporation Journal, 1964, P2820.

Sekuler, R., Tynan, P., \& Levinson, E. Visual temporal order: A new illusion. Science, 1973, 180, 210-212.

SPERLING, G. A model for visual memory tasks. Human Factors, 1963, 5, 19-31.

WEISSTEIN, N. Backward masking and models of perceptual processing. Journal of Experimental Psychology, 1966, 72, 232-240.

WINER, B. J. Statistical principles in experimental design (2nd. ed.). New York: McGraw-Hill, 1971.

(Received for publication October 31, 1977.) 